\title{
Improving cloud information over deserts from SCIAMACHY Oxygen A-band measurements
}

\author{
N. Fournier ${ }^{1}$, P. Stammes ${ }^{1}$, M. de Graaf ${ }^{1}$, R. van der $\mathbf{A}^{1}$, A. Piters ${ }^{1}$, M. Grzegorski ${ }^{2}$, and A. Kokhanovsky ${ }^{3}$ \\ ${ }^{1}$ KNMI, Climate Research and Seismology Department, De Bilt, The Netherlands \\ ${ }^{2}$ Institute of Environmental Physics, University of Heidelberg, Germany \\ ${ }^{3}$ Institute of Remote Sensing, University of Bremen, Germany
}

Received: 7 March 2005 - Published in Atmos. Chem. Phys. Discuss.: 16 August 2005

Revised: 16 November 2005 - Accepted: 6 December 2005 - Published: 25 January 2006

\begin{abstract}
The retrieval of column densities and concentration profiles of atmospheric trace gas species from satellites is sensitive to light scattered by clouds. The SCanning Imaging Absorption SpectroMeter for Atmospheric CHartographY (SCIAMACHY) instrument on the Envisat satellite, principally designed to retrieve trace gases in the atmosphere, is also capable of detecting clouds. FRESCO (Fast Retrieval Scheme for Clouds from the Oxygen A-band) is a fast and robust algorithm providing cloud information from the $\mathrm{O}_{2}$ A-band for cloud correction of ozone. FRESCO provides a consistent set of cloud products by retrieving simultaneously effective cloud fraction and cloud top pressure. The FRESCO retrieved values are compared with the SCIAMACHY Level 2 operational cloud fraction of OCRA (Optical Cloud Recognition Algorithm) but, also, with cloud information from HICRU (Heidelberg Iterative Cloud Retrieval Utilities), SACURA (SemiAnalytical CloUd Retrieval Algorithm) and the MODIS (Moderate Resolution Imaging Spectroradiometer) instrument. The results correlate well, but FRESCO overestimates cloud fraction over deserts. Thus, to improve retrievals at these locations, the FRESCO surface albedo databases are decontaminated from the presence of desert dust aerosols. This is achieved by using the GOME Absorbing Aerosol Index. It is shown that this approach succeeds well in producing more accurate cloud information over the Sahara.
\end{abstract}

Correspondence to: N. Fournier

(fournier@knmi.nl)

\section{Introduction}

SCIAMACHY (SCanning Imaging Absorption SpectroMeter for Atmospheric CHartographY) is a space-borne spectrometer that flies on Envisat since March 2002. SCIAMACHY measures the solar radiation reflected from the atmosphere in the wavelength range between 240 and $2380 \mathrm{~nm}$. This is recorded at relatively high resolution $(0.2$ to $1.5 \mathrm{~nm})$ over the range 240 to $1750 \mathrm{~nm}$, and in selected regions between 1900 and $2400 \mathrm{~nm}$. SCIAMACHY is extended as compared to its precursor GOME (Global Ozone Monitoring Experiment; (Burrows et al., 1999)) with a wavelength range in the near Infrared region and able to operate with new viewing geometries namely limb and sun and moon occultations. The primary scientific objective of SCIAMACHY is the measurement of various trace gases on a global scale (Bovensmann et al., 1999).

The trace gases that SCIAMACHY detects, like $\mathrm{O}_{3}, \mathrm{NO}_{2}$, $\mathrm{BrO}, \mathrm{SO}_{2}, \mathrm{CO}$ and $\mathrm{CH}_{4}$, occur not only in the stratosphere but also in the troposphere, where clouds reside. To detect these trace gases accurately, the presence and properties of clouds have to be known, in order to correct for the effect of clouds. The three cloud parameters that most strongly influence trace gas measurements are: cloud fraction, cloud albedo or cloud optical thickness, and cloud top pressure. Microphysical cloud parameters, like particle size and shape, are of minor importance (Koelemeijer and Stammes, 1999).

Clouds affect the path of photons through the atmosphere and therefore change the interpretation of the depth of an absorption band. Taking ozone as an example, the effect of clouds on ozone retrieval can be regarded as due to two main effects (Koelemeijer and Stammes, 1999): (1) albedo effect:

(C) 2006 Author(s). This work is licensed under a Creative Commons License. 


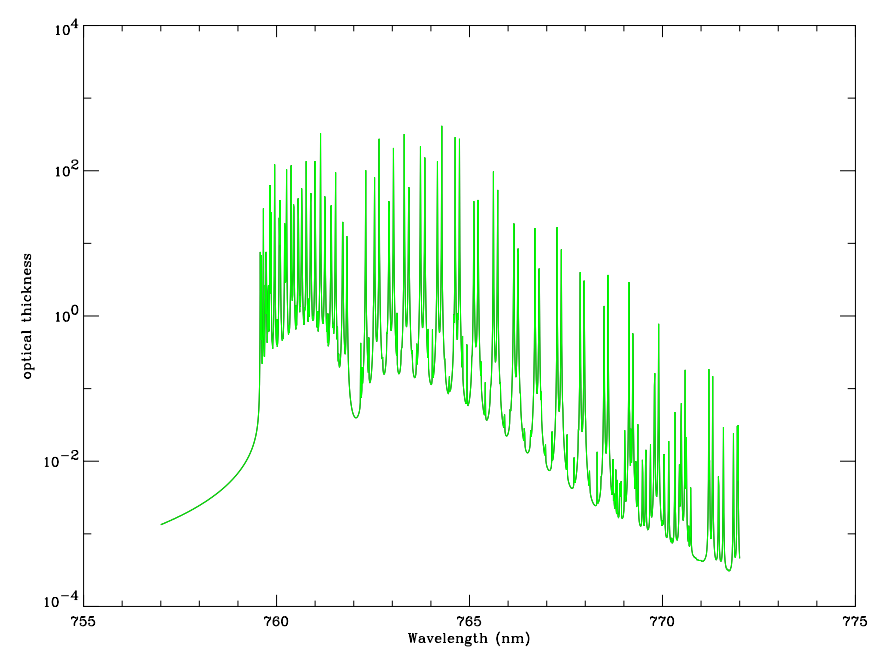

Fig. 1. The Oxygen molecular absorption optical thickness in the oxygen A band of the Mid-Latitude Summer atmosphere.

clouds act as a reflecting boundary below the ozone layer and enhance the depth of the ozone absorption bands, and (2) ghost column effect: clouds shield tropospheric ozone from observation. A third, smaller effect exists, which is the enhancement of the photon path inside clouds, causing an enhancement of the absorption band depth inside clouds (Newchurch et al., 2001).

In order to correct for the albedo effect of clouds, it is necessary to retrieve the cloud fraction and cloud albedo (or cloud optical thickness) or, equivalently, the product of cloud fraction and cloud albedo, which we call the effective cloud fraction. In order to correct for the ghost column effect of clouds, it is necessary to retrieve both the effective cloud fraction and the cloud top pressure.

The above cloud effects not only occur for $\mathrm{O}_{3}$ but also for other gases. Especially for $\mathrm{NO}_{2}$, much of which is residing in the troposphere in polluted circumstances, the ghost column effect is very important (Boersma et al., 2004). Therefore, a cloud detection algorithm suitable for trace gas retrievals for SCIAMACHY should be able to detect at least effective cloud fraction and cloud top pressure. If the cloud top pressure is available, then the tropospheric ozone column can be determined by comparing cloudy and clear pixels, using the convective-cloud-differential technique (Valks et al., 2003b).

This paper is devoted to cloud detection from SCIAMACHY using the retrieval cloud algorithm FRESCO (Koelemeijer et al., 2001). Firstly, in Sect. 2, the FRESCO algorithm is described as well as the other cloud retrieval techniques used for SCIAMACHY. In Sect. 3, FRESCO retrievals are compared with the SCIAMACHY Level 2 operational cloud fraction of OCRA and cloud information from the algorithms HICRU and SACURA as well as from the MODIS instrument on EOS/Terra. Section 4 deals with the improvement of FRESCO retrievals over deserts. Finally, our conclusions are stated in Sect. 5.

\section{Cloud retrieval techniques for SCIAMACHY}

For reasons of timeliness and co-location, for operational processing it is most practical to retrieve cloud parameters from the SCIAMACHY data itself. To this aim various SCIAMACHY channels and atmospheric absorption bands can be chosen. In the case of GOME, the Polarisation Measurement Devices (PMDs) had been used by several groups to estimate the cloud fraction. The advantage of the PMDs is that they have a better spatial resolution than the spectral channels. Von Bargen et al. (2000) have developed various cloud algorithms for GOME, among which the Optical Cloud Recognition Algorithm (OCRA) technique described in Sect. 2.2. This technique uses the color of PMD images to select cloud free scenes for a global database of cloud free reflectances. The difference between the measured PMD reflectances and those from this cloud free database is used to retrieve cloud fractions. To detect cloud pressure, however, the PMDs cannot be used because they have insufficient spectral resolution to detect absorption lines of well-mixed absorbers like oxygen. In the SCIAMACHY range there are several oxygen or oxygen-oxygen absorption bands. The strongest band is the $\mathrm{O}_{2}$ A-band at $760 \mathrm{~nm}$. Figure 1 shows the absorption lines of oxygen in this region.

In cloud retrievals from a satellite, it is very important to have a good estimate of the surface albedo. The reason is that the cloud detection is usually performed by comparing the measured reflectance with the expected reflectance from a cloud-free scene. Recently, a new spectral surface albedo database based on 5.5 years of GOME data has been prepared (Koelemeijer et al., 2003). This database is used in FRESCO and is improved in this study, as described in Sect. 4.

\subsection{FRESCO}

FRESCO has been developed as a simple, fast, and robust algorithm to provide cloud information for cloud correction of ozone concentration measurements (Koelemeijer et al., 2001). FRESCO uses the reflectance in three 1-nm wide windows of the $\mathrm{O}_{2}$ A-band: 758-759 nm, 760-761 nm, and 765$766 \mathrm{~nm}$. The measured reflectance is compared to a modeled reflectance, as computed for a simple cloud model. In this model the cloud is assumed to be a Lambertian reflector with albedo 0.8 below a clear spherical atmosphere, in which only $\mathrm{O}_{2}$ absorption is taken into account. To simulate the spectrum of a partly cloudy pixel, a simple atmospheric transmission model is used, in which the atmosphere above the ground surface (for the clear part of the pixel) or cloud (for the cloudy part of the pixel) is treated as a purely absorbing non-scattering medium. Surface albedo is required a priori for FRESCO retrievals. The surface albedo databases were deduced from a global surface Lambertequivalent reflectance (LER) database that was generated from GOME data of June 1995-December 2000 (Koelemeijer et al., 2003). The surface albedo was found by taking the 
minimum LER value of the histogram of LER values of the 5-years of GOME data. The databases are monthly averaged over this period at 1-degree resolution. The retrieved parameters are the effective cloud fraction (between 0 and 1 ) and the cloud top pressure. Absorption by oxygen inside the cloud is neglected. FRESCO is used in the fast-delivery processing of GOME ozone data (Valks et al., 2003a) and in the SCIAMACHY ozone processor TOSOMI (Eskes et al., 2005), which provides ozone data from SCIAMACHY within the ESA TEMIS project (see http://www.temis.nl).

FRESCO has been validated regionally and globally (Koelemeijer et al., 2001, 2002; Tuinder et al., 2004). However, FRESCO overestimates the cloud fraction retrievals over the Sahara region (Grzegorski et al., 2004). As it will be discussed in the Sect. 4, this is due to the higher surface albedo over this desert than assumed in the low resolution surface albedo database used by FRESCO. Secondly, FRESCO overestimates cloud top pressure by on average about $50 \mathrm{hPa}$, as compared to infrared techniques. A possible reason is the fact that photon paths inside the cloud enhance the $\mathrm{O}_{2} \mathrm{~A}$ band depth. We note that for cloud correction of ozone and other trace gases, a qualitatively similar path enhancement is expected. Thus, the FRESCO cloud top pressure is especially well suited for ozone retrieval.

\subsection{OCRA}

OCRA is used in the operational near-real-time SCIAMACHY processors (Loyola, 1998). It is a PMD algorithm using the red, green and blue PMDs for cloud fraction determination. The cloud fraction is calculated from a linear interpolation of the current PMD reflectance between a minimum (cloud free) value and a maximum (totally cloudy) value, the latter being fixed by scaling factors. An average of the results of the three PMDs is used. Reflectances of cloud free scenes are stored on a global grid. They are determined once from a large set of historic data using color distances between measured PMD color and the white point in the chromaticity diagram. Reflectances with the largest distance to the white point are selected to represent the cloud free case at a certain grid point. Currently, a database calculated from GOME PMD measurements is applied. For the totally cloudy case, one scaling factor is used for each PMD, representing the maximum reflectance.

\subsection{SACURA}

SACURA (SemiAnalytical CloUd Retrieval Algorithm) determines the cloud top pressure and geometrical thickness using measurements of the cloud reflection function in the $\mathrm{O}_{2}$ A-band (Kokhanovsky et al., 2003; Rozanov and Kokhanovsky, 2004). The algorithm uses the semi-analytical asymptotical theory applied for a cloudy medium of large optical thickness (Kokhanovsky and Rozanov, 2004). The technique considers single scattering above clouds and the cloud bi-directional reflection distribution function (BRDF) instead of assuming a Lambertian surface. This makes it particularly accurate although only completely cloudy pixels can be considered. Therefore, for broken clouds extra information on the cloud fraction is required which can be obtained using the operational SCIAMACHY cloud fraction product (OCRA). The extension of SACURA to broken cloud conditions is given by Kokhanovsky et al. (2004).

\subsection{HICRU}

Grzegorski (2003) developed an advanced PMD technique for cloud fraction retrieval, called HICRU (Heidelberg Iterative Cloud Retrieval Utilities). The SCIAMACHY algorithm uses the intensities of PMD $3(617-705 \mathrm{~nm})$. The algorithm makes use of the threshold method with lower thresholds representing cloud-free pixels while upper ones are the intensity of cloudy pixels. The lower value is produced from image sequence analysis and the upper value is calculated iteratively depending on solar zenith angle and line of sight. Cloud fraction is obtained through linear interpolation between both thresholds (Grzegorski et al., 2004).

\section{Results}

\subsection{SCIAMACHY data}

FRESCO makes use of the SCIAMACHY measurements between 758 and $766 \mathrm{~nm}$. The spectral resolution of SCIAMACHY is determined by the slit function. At these wavelengths, the full width at half maximum is $0.44 \mathrm{~nm}$ while it has a value of $0.36 \mathrm{~nm}$ and $0.57 \mathrm{~nm}$ for GOME and GOME2 , respectively. The higher spectral resolution of GOME allowed the instrument to capture more structures at the expense of undersampling. Figure 2 shows reflectivities, normalised to unity at $758 \mathrm{~nm}$, measured by SCIAMACHY for a cloud-free and a cloudy scene over the Sahara with comparable viewing and illumination angles. Clearly, the Oxygen A-band is less deep for the cloudy scene providing information on cloud-top pressure, whereas the reflectivity in the continium allows to derive the effective cloud fraction.

\subsection{MODIS data}

The SCIAMACHY operational cloud-top pressure product is derived from the ISCCP monthly mean cloud top height database, which is a climatology based on measurements of clouds from satellites (MeteoSat, GMS, GOES and NOAA). Thus, instead of using this product, MODIS (Moderate Resolution Imaging Spectroradiometer) Level 2 granules overlapping the SCIAMACHY orbit are employed to assess the accuracy of FRESCO retrievals. The co-located cloud top pressure of MODIS, onboard the Terra Platform, are produced by the infrared retrieval methods both day and night at $5-\mathrm{km}$ resolution(Platnick et al., 2003). Moreover, clouds detected via 


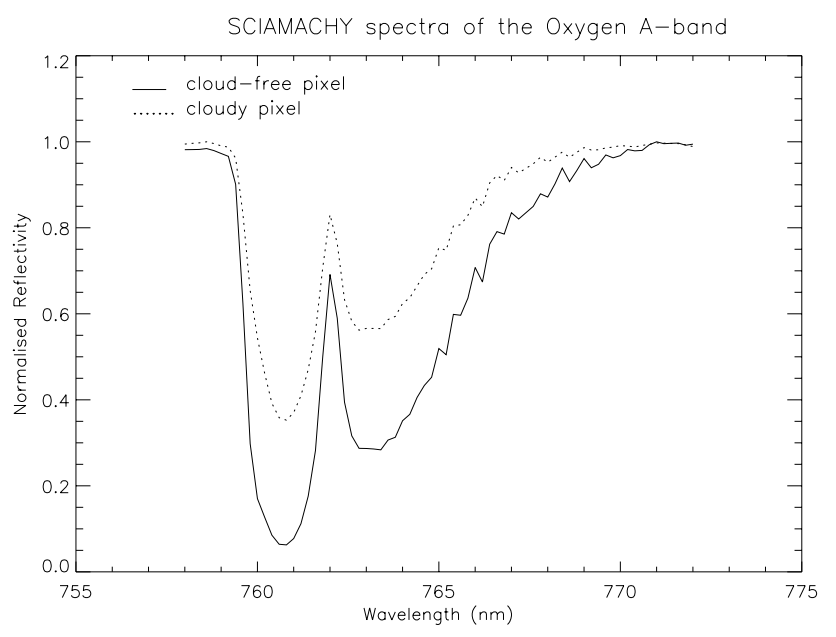

Fig. 2. Two spectra of the Oxygen A-band (cloud-free and cloudy) measured by SCIAMACHY over the Sahara, with comparable viewing and illumination angles.

MODIS images also provide a qualitative source of information of cloud cover. This will be used in this study to detect cloud-free scenes over the Sahara. However, it must be noticed that MODIS and SCIAMACHY times of measurement differ by $1-2$ hours in the different cases investigated in this study.

\subsection{FRESCO retrievals}

The absolute calibration of SCIAMACHY solar irradiance and earth radiance is not correct (Lichtenberg et al., 2005). Thus, as it affects directly the retrieval of aerosols and cloud products, a calibration correction factor of 1.20 is applied here always on FRESCO on SCIAMACHY reflectances following Acarreta et al. (2004); Acarreta and Stammes (2005). Indeed, Acarreta and Stammes (2005) showed that SCIAMACHY underestimates the reflectance by $13 \%$ at $442 \mathrm{~nm}$ reaching up to $21 \%$ at $885 \mathrm{~nm}$ as compared to MERIS.

Firstly, Fig. 3 shows FRESCO retrievals of effective cloud fraction when applying this calibration correction factor of 1.20 on SCIAMACHY radiances in the $\mathrm{O}_{2}$ A-band. This concerns the orbit 12472 (19 July 2004) containing ocean, land and desert areas.

Secondly, Fig. 4 shows the retrieved values of cloud top pressure (hPa) for the reference orbit 2510 (23 August 2002). The SCIAMACHY operational product does not correlate well with both FRESCO and MODIS values. This is due to the fact that the operational product uses the monthly mean cloud-top height from the ISCCP climatology. The correlation between MODIS and FRESCO is much better but still exhibits differences for low cloud top pressures as already observed by Koelemeijer et al. (2001). These can be explained by the different methods used to derive the cloud top pressure (Oxygen A-band versus Infra-Red). There is also a

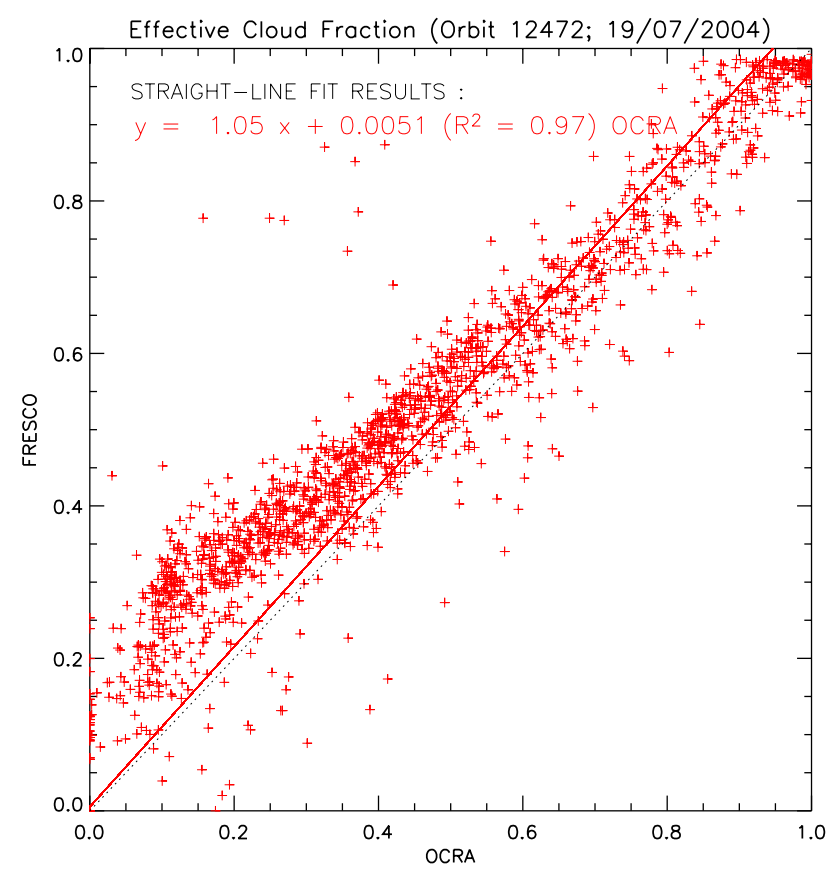

Fig. 3. Comparison of the retrieved effective cloud fractions from the old version of FRESCO with the SCIAMACHY Level 2 operational product of OCRA for orbit 12472 (19 July 2004). The dotted line is the one-to-one agreement.

systematic time difference of 1 to $2 \mathrm{~h}$ between the co-located measurements of MODIS and SCIAMACHY.

\section{FRESCO retrievals over deserts}

\subsection{Effect of aerosols on surface albedo}

Although Fig. 3 shows a good agreement between OCRA and FRESCO, FRESCO is sensitive to the type of landcover through the use of its surface albedo database. Indeed, the derived cloud fraction is particularly affected by cases with high surface albedo. In such cases, the retrieved cloud top pressure is also sensitive to the surface albedo, especially for low values of cloud fraction. It has been already underlined by Grzegorski (2003) and Tuinder et al. (2004) that while FRESCO retrievals, especially cloud fraction, correlate well with other cloud retrieval algorithms over land and oceans, FRESCO overestimates the effective cloud fraction over desert areas.

Figure 5 illustrates this point by considering the orbit 12472 (19 July 2004), as previously in Fig. 3, but focusing over the Sahara. The red and blue points represent the comparison of FRESCO with HICRU and OCRA, respectively. On one hand, Fig. 5 underlines an overestimation of FRESCO cloud fraction over the Sahara when compared with both OCRA and HICRU. On the other hand, OCRA and HICRU results match better what can be seen from a 


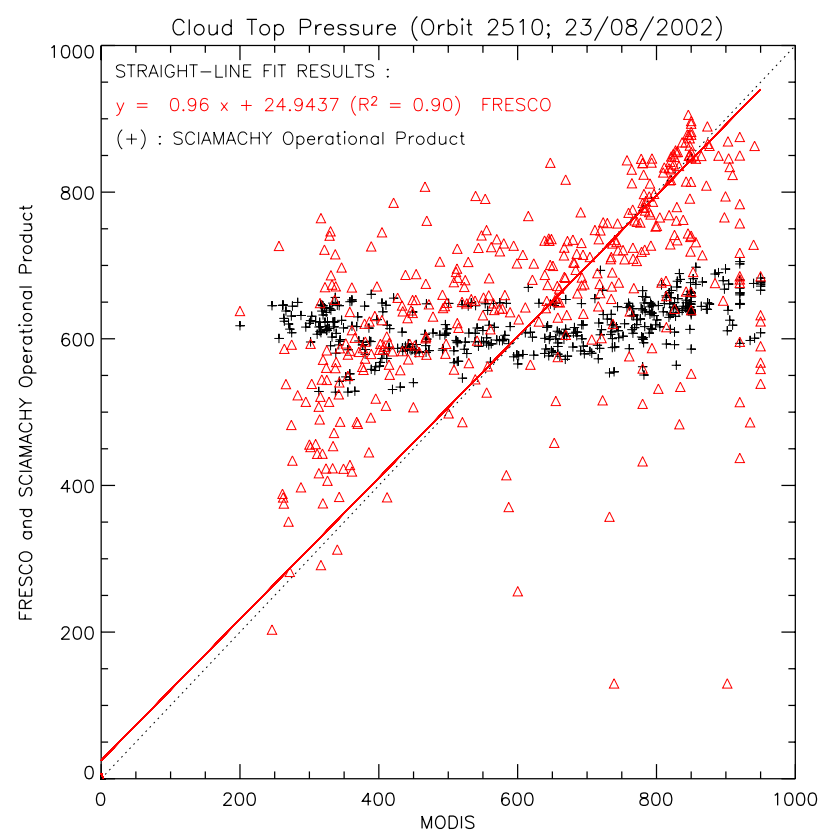

Fig. 4. Comparison of the retrieved cloud top pressure (hPa) from the old version of FRESCO and the SCIAMACHY Level 2 operational product (from ISCCP climatology) with MODIS co-located values for orbit 2510 (23 August 2002). The dotted line is the oneto-one agreement.

co-located MODIS image (Fig. 6) showing a low cloud cover at a similar time over SCIAMACHY states 14 and 15 over north-west Lybia and north Niger, respectively.

Figure 7 corroborates this behaviour of FRESCO compared to OCRA when studying another cloud-free SCIAMACHY orbit over the Sahara (Orbit 11326; 30 April 2004).

This overestimation of the effective cloud fractions is caused by the surface albedo considered in FRESCO. The surface albedo is too low for deserts. This is due to uplifting of large amounts of dust, which lower the reflectance. Then FRESCO fills the missing cloudfree reflectances with clouds. For bright surfaces like deserts, with albedos of $30 \%$ or even higher (at $760 \mathrm{~nm}$ ), aerosols may decrease the reflectance at the top of the atmosphere. Then the minimum LER from GOME, used by Koelemeijer et al. (2003) to create the surface albedo databases, does not yield the aerosol-free albedo but the aerosol-contaminated albedo.

\subsection{Decontamination of the surface albedo}

The monthly surface albedo databases used in FRESCO, namely at 758 and $772 \mathrm{~nm}$, have been de-contaminated for the presence of desert dust aerosols. This has been achieved in two steps : (1) detection of the desert areas with the monthly LER surface albedo databases at $670 \mathrm{~nm}$; (2) detection of dust aerosols using the GOME Absorbing Aerosol Index (AAI). The AAI from GOME uses the reflectances

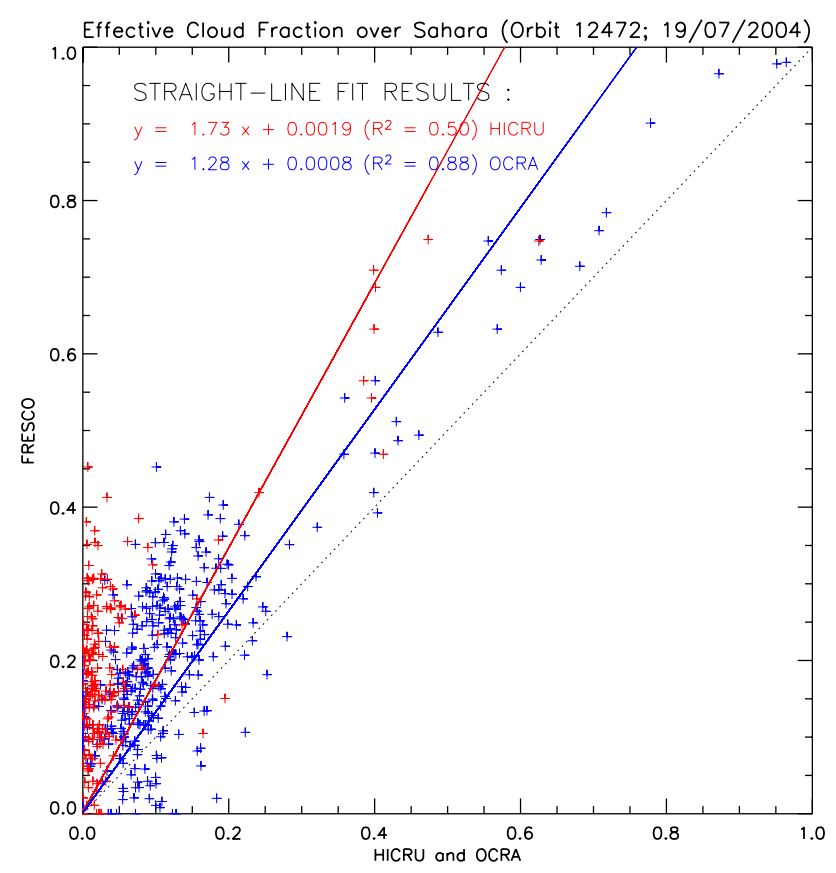

Fig. 5. Comparison of the retrieved effective cloud fraction from the old version of FRESCO and the products from OCRA (blue) and HICRU (red) for orbit 12472 (19 July 2004). The results are shown for SCIAMACHY states 14 and 15. The dotted line is the one-to-one agreement.

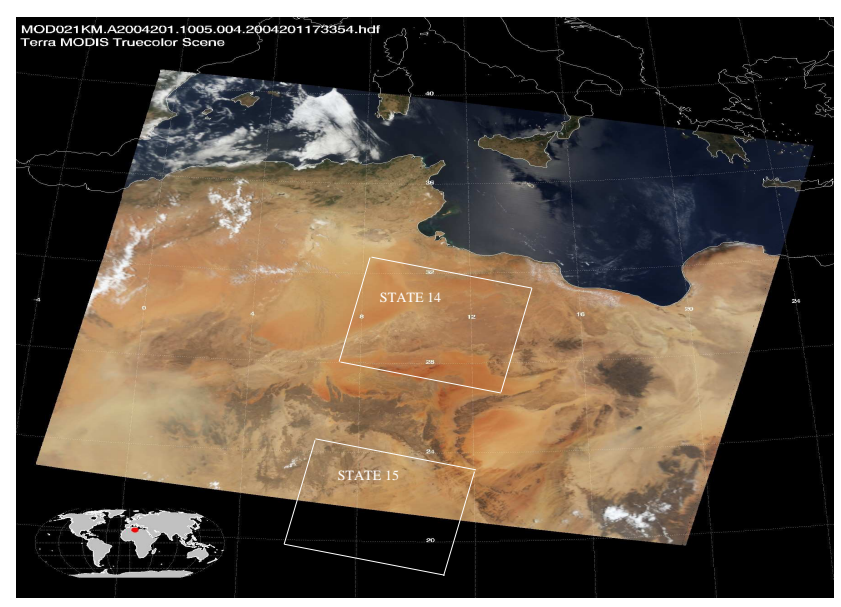

Fig. 6. MODIS image over the Sahara co-located with SCIAMACHY orbit 12472 (19 July 2004; $10 \mathrm{~h} \mathrm{05).} \mathrm{The} \mathrm{geolocation} \mathrm{of}$ the States 14 and 15 of the SCIAMACHY swath are also included.

at two UV wavelengths, 335 and $380 \mathrm{~nm}$. The color of the scene at these two wavelengths is compared to the color of a purely Rayleigh scattering atmosphere. The color difference, expressed as the AAI, indicates the presence of absorbing aerosols like desert dust (De Graaf et al., 2005). Figure 8 shows an example (July) of the surface albedo database at $670 \mathrm{~nm}$. In this study, monthly averaged values of the AAI 


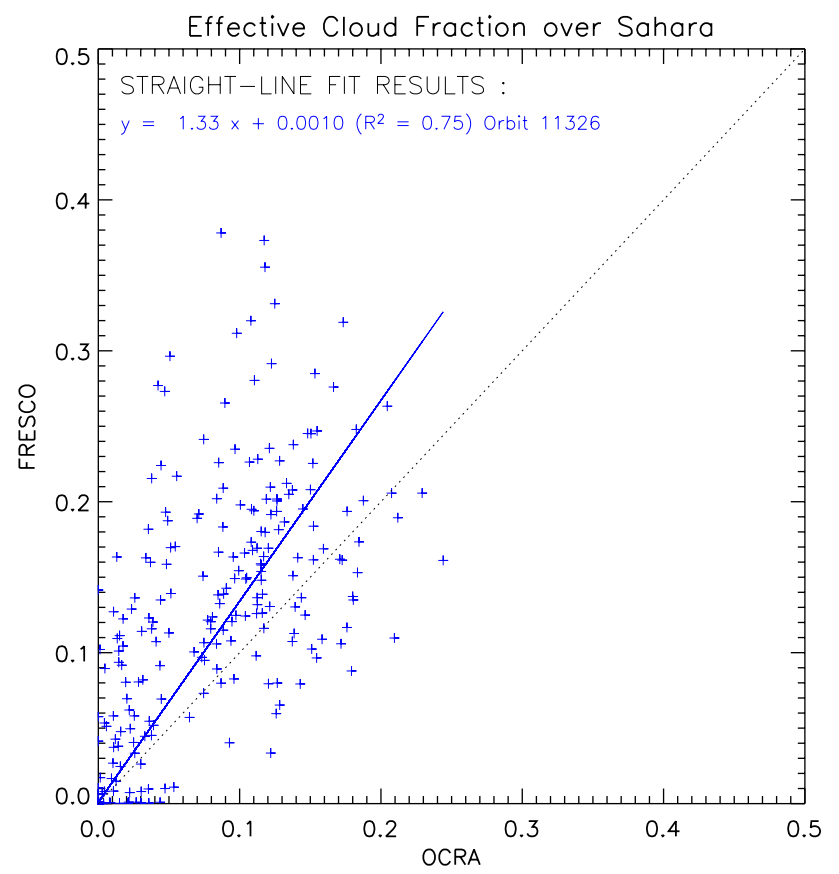

Fig. 7. Comparison of the retrieved effective cloud fraction from the old version of FRESCO and OCRA for orbit 11326 (30 April 2004). The results are shown for locations over the Sahara. The dotted line is the one-to-one agreement.

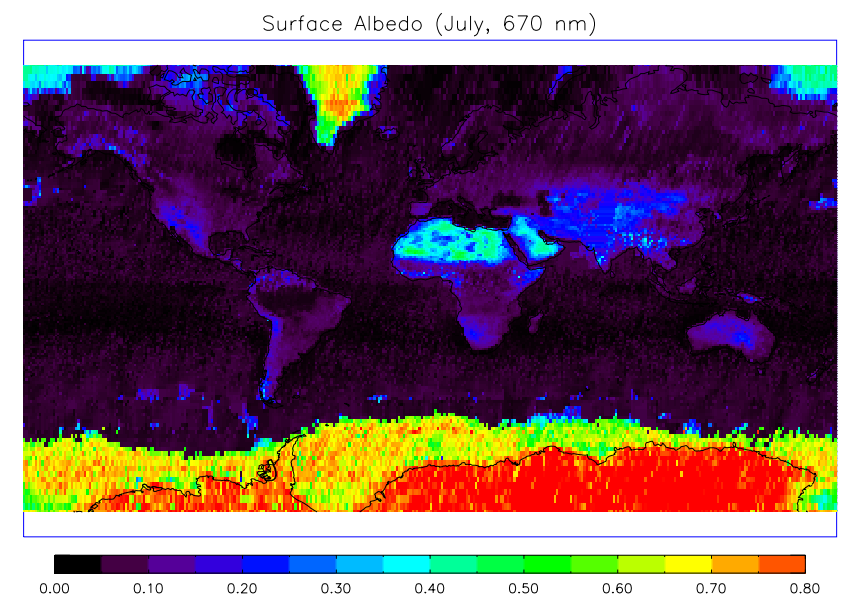

Fig. 8. Global map of surface albedo at $670 \mathrm{~nm}$ for July at 1-degree resolution (Koelemeijer et al., 2003).

were created over the 6-years of available AAI (1995-2000; http://www.temis.nl). Figure 9 gives the AAI 6-years average for July but monthly values are available from 1995 to 2000 (De Graaf et al., 2005).

Firstly, deserts have been characterised as surfaces with an albedo at $670 \mathrm{~nm}$ above 0.20 (Koelemeijer et al., 2003). This does not hold for high latitudes at which locations, anyway, no AAI values were retrieved as it can be seen in Fig. 9. Sec-

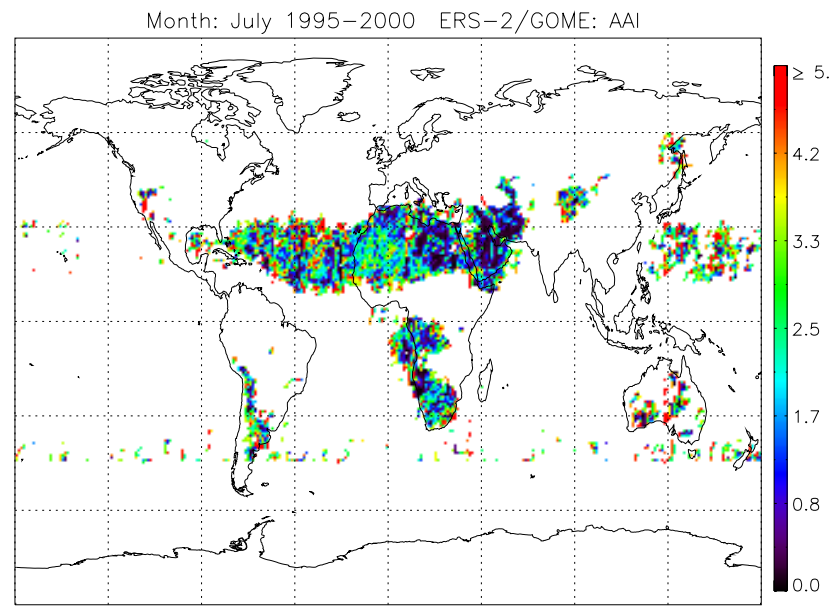

Fig. 9. Global map of the 1995-2000 July mean GOME AAI from De Graaf et al. (2005).

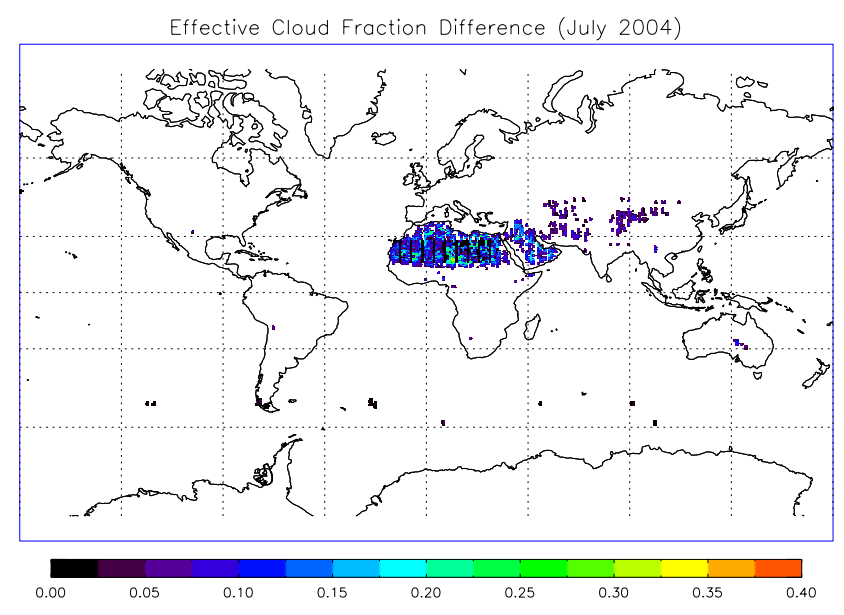

Fig. 10. Difference between the old and new FRESCO retrievals of effective cloud fraction for July 2004. The new version of FRESCO incorporates the updated surface albedo databases.

ondly, high values of AAI indicate the presence of absorbing aerosol layers. Thus, an AAI threshold value of 1.0 has been chosen to correct the monthly surface albedo databases over deserts.

The correction on the surface albedo when the two previous conditions (desert location and AAI larger than 1.0) are full-filled is $+20 \%$. This value has been chosen following a series of sensitivity tests in the range $1-40 \%$. A serie of twelve cloud-free and five cloudy scenes over the Sahara have been chosen using MODIS images. The surface albedo correction was changed (+1 to $+40 \%)$ to evaluate the value for which FRESCO succeeds to retrieve the appropriate effective cloud fraction. An increase of the surface albedo of $+20 \%$ was appropriate to improve the retrieved cloud fraction for these cloud-free scenes over the Sahara. The effect on FRESCO cloud fraction can be seen in Fig. 10. The map 


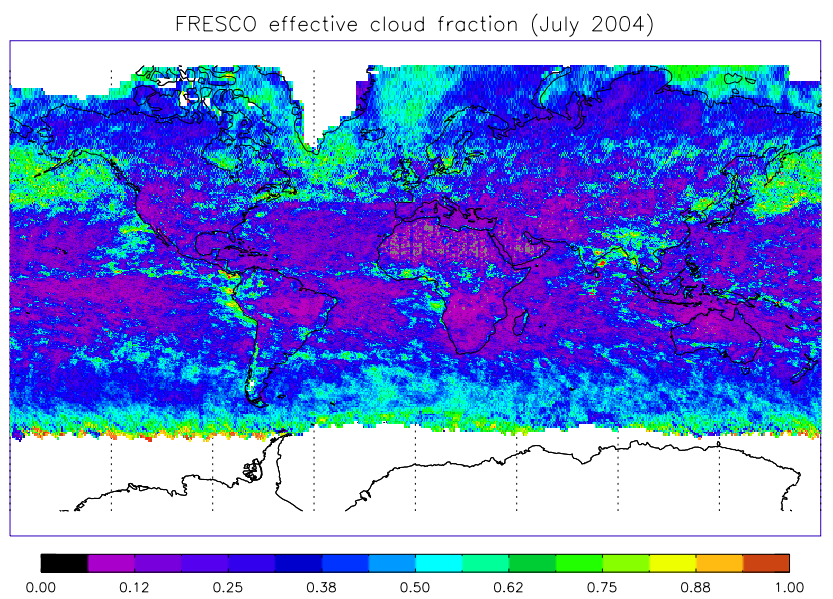

Fig. 11. Monthly average effective cloud fraction from FRESCO (new version) using SCIAMACHY measurements of July 2004.

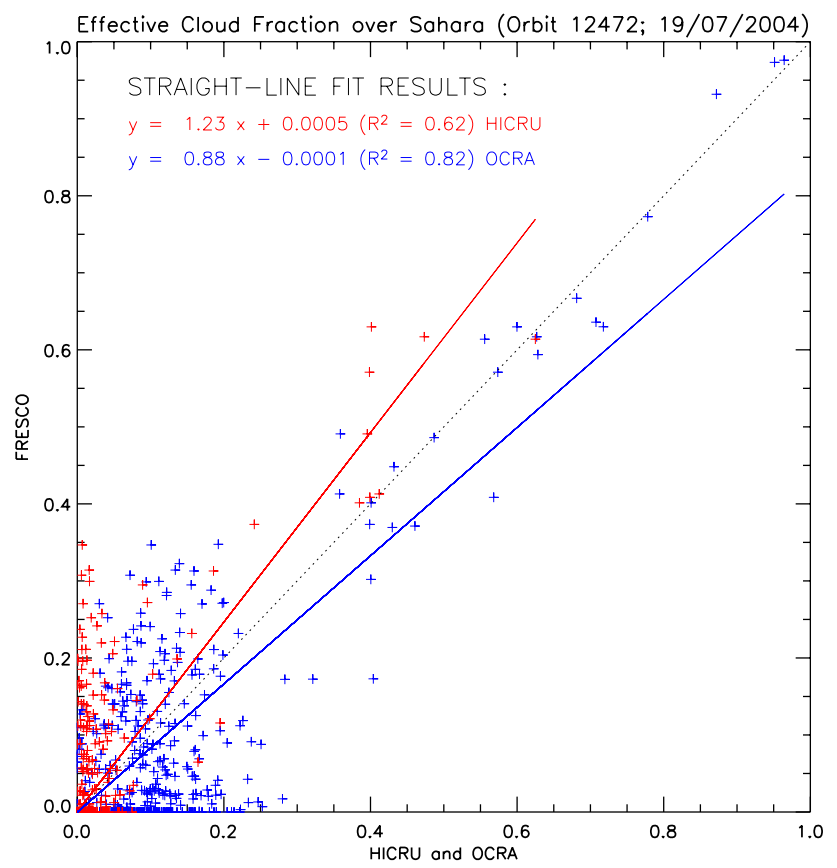

Fig. 12. Comparison of the retrieved effective cloud fraction from the new version of FRESCO and the products from OCRA (blue) and HICRU (red) for orbit 12472 (19 July 2004). The results are shown for SCIAMACHY states 14 and 15. The dotted line is the one-to-one agreement.

compares the FRESCO averaged retrievals for all data of July 2004 with (new version: Fig. 11) and without this correction (old version). The improvement of the surface albedo values allows FRESCO to retrieve more accurately cloud-free scenes over deserts. Indeed, the new version exhibits lower values of effective cloud fraction over desert areas, mainly the Sahara. The improvement is corroborated in Fig. 12 in the comparison with OCRA and HICRU shown previ-

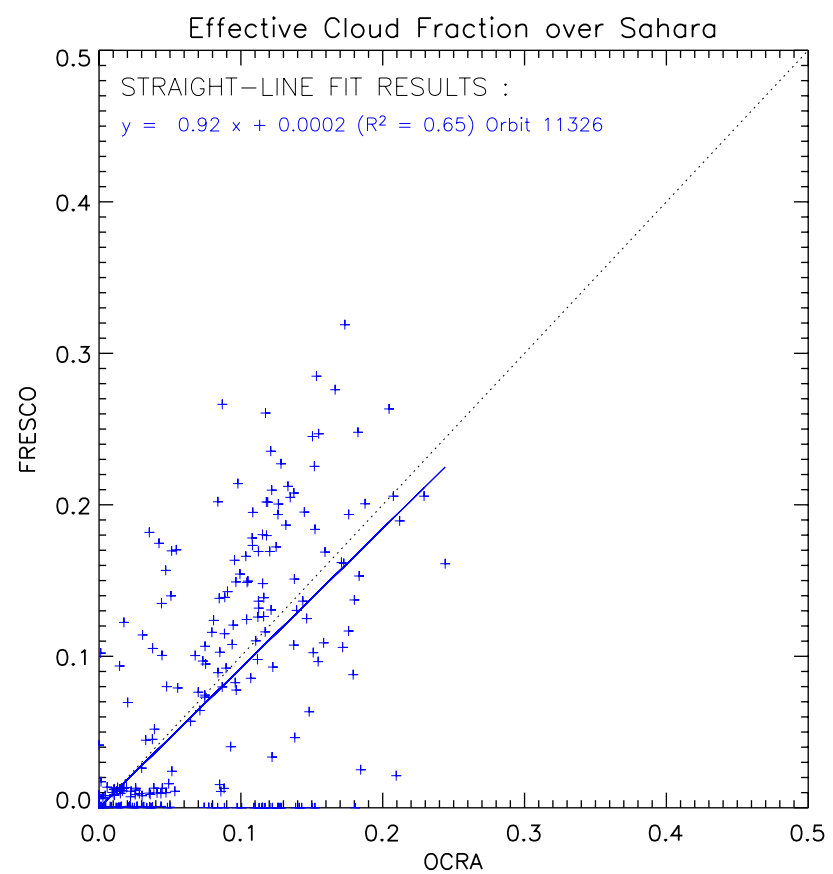

Fig. 13. Comparison of the retrieved effective cloud fraction from the new version of FRESCO and OCRA for orbit 11326 (April 30, 2004). The results are shown for locations over the Sahara. The dotted line is the one-to-one agreement.

ously (Fig. 5) for orbit 12472 over the Sahara. This is confirmed, although the new correlation coefficient is slightly lower (0.65 instead of 0.75), in Fig. 13 which considers orbit 11326 in the comparison between FRESCO and OCRA (slope of 0.92 instead of 1.33 in Fig. 7).

\section{Cloudy scene over Sahara}

Moreover, it is important to check that the new approach also allows to reproduce accurately cloudy scenes over deserts. Using a MODIS image, a specific cloudy scene over the Sahara from orbit 7591 (13 August 2003) is investigated. Figure 14 gives the cloud cover from a PMD imager while Figs. 15 and 16 show the retrieved effective cloud fractions from the old and new versions of FRESCO, respectively. This illustrates the adequacy of the new algorithm to retrieve the appropriate amount of clouds when compared with the cloud cover from the PMD imager. The new retrievals (Fig. 16) show fully cloudy pixels with a clear sky background which was not the case before for this scene as underlined in Grzegorski et al. (2004).

The accuracy of the new version of FRESCO in retrieving the appropriate cloud information over desert is corroborated in Fig. 17. This compares the retrieved cloud top pressure values $(\mathrm{hPa})$ from FRESCO with the results of MODIS and the SACURA cloud algorithm of Kokhanovsky et al. (2003) 


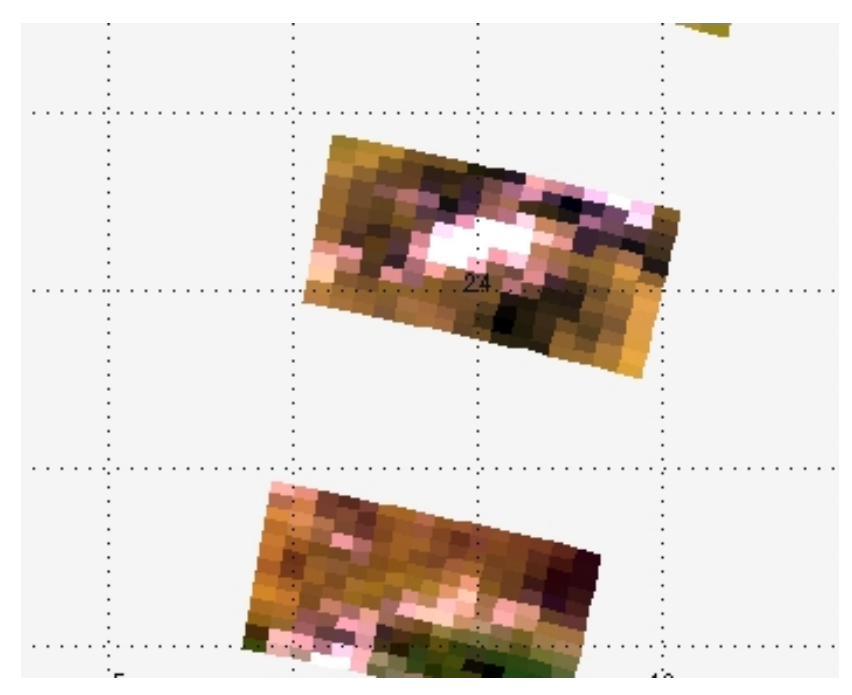

Fig. 14. Cloud cover from a PMD imager for orbit 7591 (13 August 2003) over the Sahara.

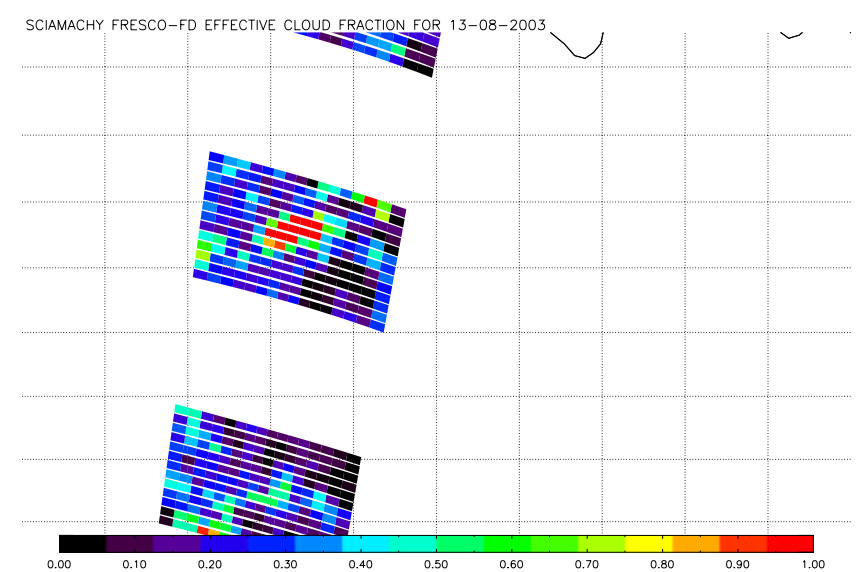

Fig. 15. Retrieved effective cloud fractions from the old version of FRESCO for orbit 7591 (13 August 2003) over the Sahara.

and Rozanov and Kokhanovsky (2004) for SCIAMACHY orbit 7591 (13 August 2003; state 13) over south-east Algeria (Fig. 18). The appoaches correlate reasonably well showing that FRESCO retrieves now more accurately the effective cloud fraction over deserts as well as still reasonnable cloud top pressures when there are some clouds at these locations. For the same comparison, the previous version of FRESCO produced slopes of $0.85\left(\mathrm{R}^{2}=0.9\right)$ and $1.06\left(\mathrm{R}^{2}=0.78\right)$ compared to SACURA and MODIS, respectively. This shows that the improvement in effective cloud fraction leads to slightly higher FRESCO cloud top pressures but does not alter significantly the correlation with other cloud products.

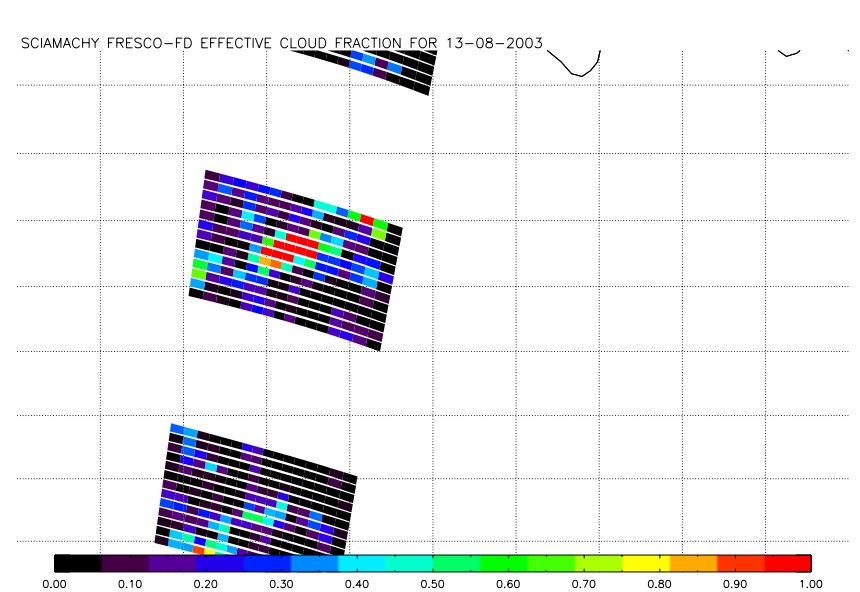

Fig. 16. Retrieved effective cloud fractions from the new version of FRESCO with corrected surface albedo for orbit 7591 (13 August 2003) over the Sahara.

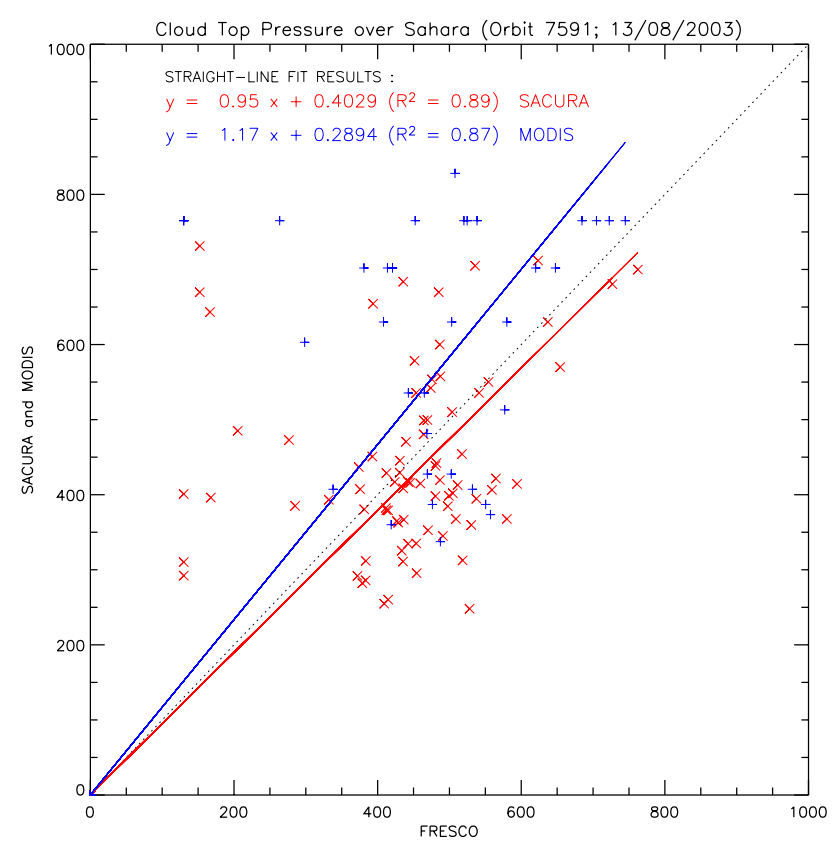

Fig. 17. Comparison of the retrieved cloud top pressure (hPa) from the new version of FRESCO with MODIS (blue) and SACURA (red) for orbit 7591 (13 August 2003; state 13) over the Sahara. The dotted line is the one-to-one agreement.

\section{Conclusions}

In this study, the FRESCO cloud product over deserts for SCIAMACHY has been improved. The surface albedo used a priori in the cloud algorithm did not take into account the effect of dust aerosols over desert areas. Therefore, the monthly surface albedo databases at 758 and $772 \mathrm{~nm}$ have been decontaminated from this effect by using the GOME Absorbing Aerosol Index. The study shows that this 


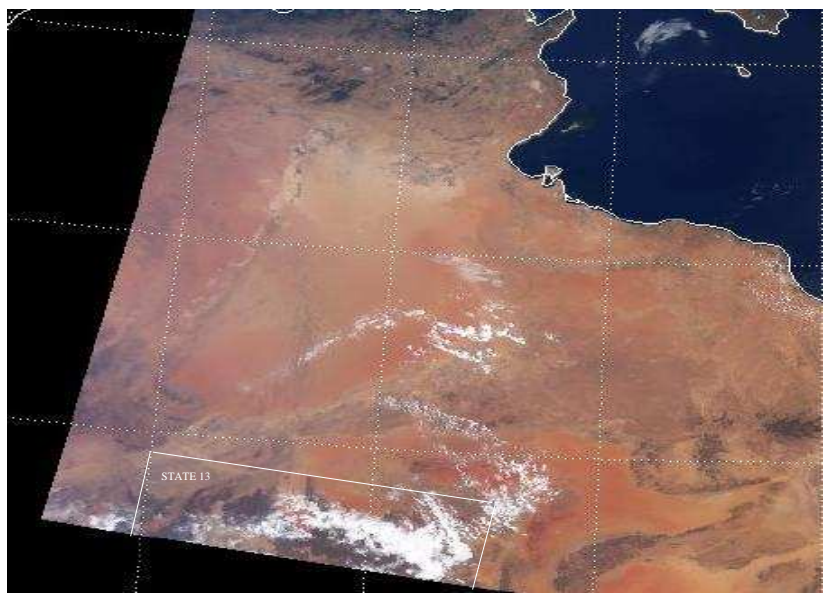

Fig. 18. MODIS image over the Sahara co-located with SCIAMACHY orbit 7591 (13 August 2003; 9h 45). The geolocation of the State 13 of the SCIAMACHY swath is also included.

approach succeeds well in improving FRESCO retrievals of effective cloud fraction and cloud top pressure over the Sahara for both cloud-free and cloudy scenes. A better agreement is obtained in qualitative comparisons with images from the MODIS instrument and also in quantitative comparisons with other SCIAMACHY cloud algorithms such as OCRA, HICRU and SACURA.

Acknowledgements. We would like to thank DLR and ESA/ESRIN for providing SCIAMACHY calibrated Level 1 and Level 2 data. This work is funded by the Netherlands Agency for Aerospace Programmes (NIVR) SCIAMACHY validation project. A. Kokhanovsky acknowledges the support of DFG Project BU 688/8-1.

Edited by: P. C. Simon

\section{References}

Acarreta, J. R., Stammes, P., and Tilstra, L. G.: Reflectance comparison between SCIAMACHY and MERIS, Proceedings of ENVISAT ACVE2 workshop, SP-562, 3-7 May 2004.

Acarreta, J. R. and Stammes, P.: Calibration comparison between SCIAMACHY and MERIS on board ENVISAT, IEEE Geoscience and Remote Sensing Letters (GRSL), 2, 31-35, doi:10.1109/LGRS.2004.838348, 2005.

Boersma K. F., Eskes, H. J., and Brinksma, E. J.: Error analysis for tropospheric $\mathrm{NO}_{2}$ retrieval from space, J. Geophys. Res., 109, D04311, doi:10.1029/2003JD003962, 2004.

Bovensmann, H., Burrows, J. P., Buchwitz, M., Frerick, J., Noel, S., Rozanov, V., Chance, K. V., and Goede, A. P. H.: SCIAMACHY; Mission objectives and measurement modes, J. Atmos. Sci., 56, 127-150, 1999.

Burrows, J. P., Weber, M., Buchwitz, M., et al.: The Global Ozone Monitoring Experiment (GOME): Mission Concept and First Scientific Results, J. Atmos. Sci., 56, 151-175, 1999.
De Graaf, M., Stammes, P., Torres, O., and Koelemeijer, R. B A.: Absorbing Aeorosol Index: sensitivity, analysis, application to GOME and comparison with TOMS, J. Geophys. Res., 110, D010201, doi:10.1029/2004JD005178, 2005.

Eskes H. J., van der A, R. J., Brinksma, E. J., Veefkind, J. P., de Haan, J. F., and Valks, P. J. M.: Retrieval and validation of ozone columns derived from measurements of SCIAMACHY on Envisat, Atmos. Chem. Phys. Discuss., 5, 4429-4475, 2005, SRef-ID: 1680-7375/acpd/2005-5-4429.

Grzegorski, M.: Determination of cloud parameters for GOME with broad band spectrometers and from absorption bands of oxygen dimer, Diplomarbeit, Heidelberg University, 2003.

Grzegorski, M., Frankenberg, C., Platt, U., Wenig, M., Fournier, N., Stammes, P., and Wagner, T.: Determination of cloud parameters from SCIAMACHY data for the correction of tropospheric trace gases, in: Proceedings of EnviSat Symposium, SP572, Salzburg, Austria, 6-10 September 2004.

Koelemeijer, R. B. A. and Stammes, P.: Effects of clouds on the ozone column retrieval from GOME UV measurements, J. Geophys. Res., D104, 8281-8294, 1999.

Koelemeijer, R. B. A., Stammes, P., Hovenier, J. W., and de Haan, J. F.: A fast method for retrieval of cloud parameters using oxygen A-band measurements from the Global Ozone Monitoring Instrument, J. Geophys. Res., D106, 3475-3490, 2001.

Koelemeijer, R. B. A., Stammes, P., de Haan, J. F., and Hovenier, J. W.: Global distributions of effective cloud fraction and cloud top pressure derived from oxygen A-band spectra measured by the Global Ozone Monitoring Instrument: Comparison to ISCCP data, J. Geophys. Res., 107 (D12), D124151, doi:10.1029/2001JD000840, 2002.

Koelemeijer, R. B. A., de Haan, J. F., and Stammes, P.: A database of spectral surface reflectivity in the range $335-772 \mathrm{~nm}$ derived from 5.5 years of GOME observations, J. Geophys. Res., 108 (D2), D24070, doi:10.1029/2002JD002429, 2003.

Kokhanovsky, A. A., Rozanov, V. V., Zege, E. P., Bovensmann, H., and Burrows, J. P.: A semianalytical cloud retrieval algorithm using backscattered radiation in $0.4-2.4 \mu \mathrm{m}$ spectral region, $\mathrm{J}$ Geophys. Res., 108 (D1), D14008, doi:10.1029/2001JD001543, 2003.

Kokhanovsky, A. A., Rozanov, V. V., von Hoyningen-Huene, W., Bovensmann, H., Burrows, J. P., and Baltink, H. K.: The determination of cloud altitudes using SCIAMACHY onboard ENVISAT, IEEE Transactions on Geosciences and Remote Sensing, Letters, v.1, 211-214, 2004.

Kokhanovsky, A. A. and Rozanov, V. V.: The physical parameterization of the top-of-atmosphere reflection function for a cloudy atmosphere-underlying surface system: the oxygen A-band case study, J. Quant. Spectr. Rad. Transfer, 85, 35-55, 2004.

Lichtenberg, G., Kleipool, Q., Krijger, J. M., et al.: SCIAMACHY Level1 data: Calibration concept and in-flight calibration, Atmos. Chem. Phys. Discuss., 5, 8925-8977, 2005,

SRef-ID: 1680-7375/acpd/2005-5-8925.

Loyola, D.: A New Cloud Recognition Algorithm for Optical Sensors, In IEEE International Geoscience and Remote Sensing Symposium, volume 2 of IGARSS 1998 Digest, p. 572-574, Seattle, 1998.

Newchurch, M. J., Liu, X., Kim, J. H., and Bhartia, P. K.: On the accuracy of Total Ozone Mapping Spectrometer retrievals over tropical cloudy regions, J. Geophys. Res., 106 (D23), 32315 
32 326, doi:10.1029/2000JD000151, 2001.

Platnick, S., King, M. D., Ackerman, S. A., Menzel, W. P., Baum, B. A., Riédi, J. C., and Frey, R. A.: The MODIS Cloud Products: Algorithms and Examples from Terra, in: IEEE Transactions on Geoscience and Remote Sensing, 41, 2, 459-473, 2003.

Rozanov, V. V. and Kokhanovsky, A. A.: Semianalytical cloud retrieval algorithm as applied to the cloud top altitude and the cloud geometrical thickness determination from top-of-atmosphere reflectance measurements in the oxygen A band, J. Geophys. Res., 109, D05202, doi:10.1029/2003JD004104, 2004.

Tuinder, O. N. E., de Winter-Sorkina, R., and Builtjes, P.: Retrieval methods of effective cloud cover from the GOME instrument: an intercomparison, Atmos. Chem. Phys., 4, 255-273, 2004,

SRef-ID: 1680-7324/acp/2004-4-255
Valks, P. J. M., Piters, A. J. M., Lambert, J. C., Zehner, C., and Kelder, H.: A Fast Delivery System for the retrieval of near-real time ozone columns from GOME data, Int. J. Remote Sensing, 24, 423-436, 2003a.

Valks, P. J. M., Koelemeijer, R. B. A., van Weele, M., van Velthoven, P., Fortuin, J. P. F., and Kelder, H.: Variability in tropical tropospheric ozone: Analysis with Global Ozone Monitoring Experiment observations and a global model, J. Geophys. Res., 108, D114329, doi:10.1029/2002JD002894, 2003 b.

Von Bargen, A., Kurosu, T. P., Chance, K., Loyola, D., Aberle, B., and Spurr, R. J.: Cloud retrieval algorithm for GOME, Final Report, ER-TN-DLR-CRAG-007, ESA/ESTEC, October 2000. 